\title{
Cardio-oncology: a new medical issue
}

\author{
D Cardinale, A Colombo, G Lamantia, N Colombo, M Civelli, G De Giacomi, C Pandini, MT Sandri and CM Cipolla
}

Cardiology Unit and Laboratory Medicine Unit, European Institute of Oncology, IRCCS, 20141 Milan, Italy.

\begin{abstract}
Due to the increasing number of long-term cancer survivors, the ageing of the population, as well as the increased incidence and prevalence of oncologic and cardiovascular diseases, the number of patients presenting oncologic and cardiologic co-morbidities are increasing. Accordingly, there is a rapidly growing need for a comprehensive and proficient management of patients in whom the two comorbidities exist, and for cancer patients whose clinical history and oncologic treatment put them at higher risk for developing cardiovascular problems, in order to provide the optimal treatment in every situation, and to avoid the possibility that the development of the second disease does not lead to a reduction of therapeutic opportunities for the patient. A new discipline, cardio-oncology, has been created to deal with this need. Its aim is to investigate new strategies, collect new evidence-based indications and develop interdisciplinary expertise in order to manage this growing category of patients. Cardio-oncology deals with the following main clinical and research areas: early diagnosis of cardiotoxicity, risk stratification and preventions, treatment and monitoring of cardiotoxicity.
\end{abstract}

Published: $15 / 12 / 2008$

Received: 12/11/2008

ecancer 2008, 2:126 DOI: 10.3332/ecancer.2008.126

Copyright: (c) the authors; licensee ecancermedicalscience. This is an Open Access article distributed under the terms of the Creative Commons Attribution License (http://creativecommons.org/licenses/by/2.0), which permits unrestricted use, distribution, and reproduction in any medium, provided the original work is properly cited.

Competing Interests: The authors have declared that no competing interests exist.

Corresponding to D Cardinale. Email: daniela.cardinale@ieo.it 
The survival rate of patients with cancer, as well as those with cardiovascular disease has greatly increased over the past three decades $[1,2,3]$. This is partly due to improvements in pharmacological treatment and in surgery procedures and because of the reduction and control of major risk factors. On the other hand, due to the ageing of the population, the incidence and prevalence of oncologic and cardiovascular disease, as well as the number of patients presenting oncologic and cardiologic co-morbidities, are increasing.

Because of overlapping risk factors, such as obesity, hormone replacement therapy and, in particular, smoking, heart disease patients are likely to have a higher risk of cancer than the general population $[4,5]$.

Conversely, the development of effective prevention screening and treatment strategies for many cancers, particularly in the early stages of the disease, has resulted in an enormous population of long-term cancer survivors. According to estimates from the National Cancer Institute and the Centres for Disease Control and Prevention, there were more than ten million cancer survivors in the United States alone in 2002 [6]. Many of these survivors have had radiation or chemotherapy (CT) treatments, with potential long-term cardiovascular toxicities, that may ultimately attenuate the clinical success of oncologic treatments. Data from recent oncology literature indicate that more than half of all patients exposed to chemotherapy will show some degree of cardiac dysfunction ten to 20 years after CT, $5 \%$ will develop overt heart failure, and $40 \%$ will experience arrhythmias [7]. This population shows an eightfold higher cardiovascular mortality when compared to the general population [8].

For these reasons, there is a rapidly growing need for comprehensive and professional management aimed at patients in whom the two co-morbidities exist, and at cancer patients whose clinical history and oncologic treatment put them at higher risk for developing cardiovascular problems. This must be accomplished in order to provide optimal treatment in every situation, and to avoid the possibility that the onset of a second disease may lead to a reduction of therapeutic opportunities and negative long-term results.

Indeed, when a cardiac patient develops an oncological problem, the cardiologist often loses interest in him or her and tends to inherit a defeatist attitude, which may exclude the patient from other intensive treatment and/or intervention possibilities. Conversely, when a cancer patient develops a cardiologic problem, he/she is invariably excluded from first-line, more aggressive (and therefore, more effective) therapeutic strategies, negatively impacting his oncologic outcome.

The final result is that this patient goes beyond the jurisdiction of both the cardiologist and the oncologist, and there is no one who takes it upon himself to give this patient comprehensive care. As a consequence, the management of such patients is limited, disjointed and often inadequate. The patient feels left alone and unprotected. This behaviour may lead to negative prognostic influence during the course of the two illnesses, whereas, under different circumstances, the patient may have been effectively treated.

In order to deal with this need, a new discipline, cardiooncology, has been created. Its aim is to investigate innovative strategies, collect evidence-based indications, and to develop interdisciplinary expertise, which will be able to manage this new and growing category of patients, to guarantee correct clinical administration, and to provide the best therapeutic opportunities, also in terms of the impact on prognosis of the two concomitant diseases, for these more complex patients.

\section{Diagnosis of cardiotoxicity}

Cardiotoxicity is a common complication of CT. The clinical manifestation of CT can range, in its more typical form, chronic cardiotoxicity, from transient asymptomatic left ventricular dysfunction to cardiac death $[9,10]$.

This is a growing problem in the setting of clinical oncology, given the increasing number of long-term cancer survivors, the tendency to use progressively higher doses of anthracyclines (AC), the introduction of new anti-tumour agents with possible cardiotoxic properties and combined treatments with synergistic harmful effects [10-13]. The clinical implications of cardiotoxicity are particularly relevant in those cancer patients in whom the onset of cardiac dysfunction, even asymptomatic, seriously limits their therapeutic opportunities and negatively impacts their clinical outcome. Therefore, early identification of patients at risk for cardiotoxicity represents a primary goal for both cardiologists and oncologists, allowing for the definition of personalized antineoplastic therapeutic strategies and/or interventions [14].

To detect CT-induced cardiac damage in an early phase, regular cardiac function assessment is, at present, recommended by oncologic guidelines. Cardiologic surveillance is required during $\mathrm{CT}$, to allow for the administration of the highest dose without inducing cardiac injury, and after 


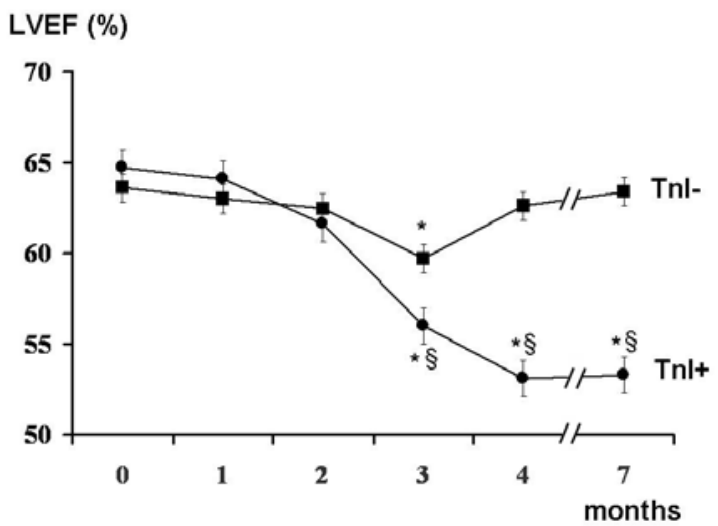

Figure 1: Left ventricular ejection fraction (LVEF) at baseline and during the seven months of follow-up of troponin I positive (TnI+) and negative (Tnl-) patients.

completion of the CT to identify cardiac damage at an early preclinical stage. This is carried out in order to limit, by means of pharmacologic intervention, the progression of cardiac dysfunction.

At least three international consensus guidelines recommend evaluation of left ventricular ejection fraction (LVEF) at the beginning of antineoplastic therapy, after administration of half the total anthracyclines cumulative dose, and before every following dose [15-17]. It is also recommended during followup, and LVEF evaluation at three, six, and 12 months after the end of treatment $[10,18]$. A decline of LVEF by more than $10 \%$, associated to an absolute LVEF value $<50 \%$, is suggested as a criterion for suspending treatment [19].

The weak point of such an approach is that it is too late. In fact, cardiac damage is usually detected when functional impairment has already occurred [20,21]. Many doubts have been raised about the utility of monitoring the cardiac function by LVEF evaluation by means of most utilized methods in clinical practice, including echocardiography and radionuclideangiocardiography, since the value of this monitoring seems to be neither sensitive nor specific enough to give an early prediction of the development of cardiac dysfunction after CT. Actually, it permits the identification of cardiac damage only after the onset of cardiac dysfunction, not allowing for any early strategy able to prevent future cardiomyopathy (CMP) [20]. On the other hand, the evidence of unaffected heart function does not exclude the possibility of further cardiac deterioration [2224].

Hence, there is growing expectation for newer, non-invasive and cost-effective diagnostic tools for the early identification of patients prone to developing drug-induced cardiotoxicity.
In our clinical practice, we utilize different markers for the early identification of patients at increased risk of cardiotoxicity: troponin I and N-terminal-proB-type natriuretic peptide (NTproBNP). For both of these, an accurate predictive value has been demonstrated by our recent investigations.

\section{Markers of myocardial damage: troponin I}

Troponin I (Tnl) is a protein present exclusively in the myocardial cells. The Tnl plasma concentration is a wellestablished, specific and sensitive marker of myocardial injury, widely used for the diagnosis and the risk stratification of acute coronary syndromes. More recently, Tnl has been utilized to detect cardiac damage in other clinical settings, such as heart failure, acute pulmonary embolism, renal failure, sepsis and septic shock and stroke $[25,26]$. Evidence of troponin's release after CT has previously been demonstrated in animal models and in clinical studies $[27,28]$.

In previous studies, we demonstrated that $\mathrm{Tnl}$ is a sensitive and specific marker of myocardial injury after high-dose $\mathrm{CT}$, and that it is able to predict, in a very early phase, the development of future ventricular dysfunction, as well as its severity $[29,30]$. Indeed, patients showing an increase of this marker soon after the end of CT significantly decreased systolic ventricular function in the months following (Figure 1). Moreover, in our studies, we found a strong relationship between the maximal Tnl value measured soon after CT and the degree of LVEF reduction during the follow-up (Figure 2).

In a more recent work, a large population with a long follow-up (48 months) and a wide spectrum of cardiac events was 


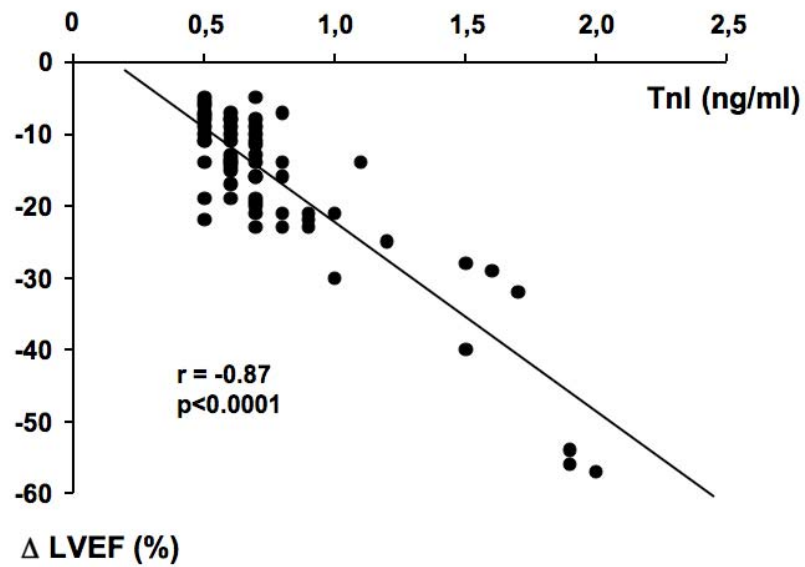

Figure 2: Scatterplot of left ventricular ejection fraction (LVEF) changes against troponin I (Tnl) value in Tnl+ patients. Modified from Cardinale et al [29].

$*=p<0.001$ versus baseline (month 0 ); $\mathrm{fl}=\mathrm{p}<0.001$ versus Tnl-group. Data are shown as mean $\pm 95 \% \mathrm{Cl}$.

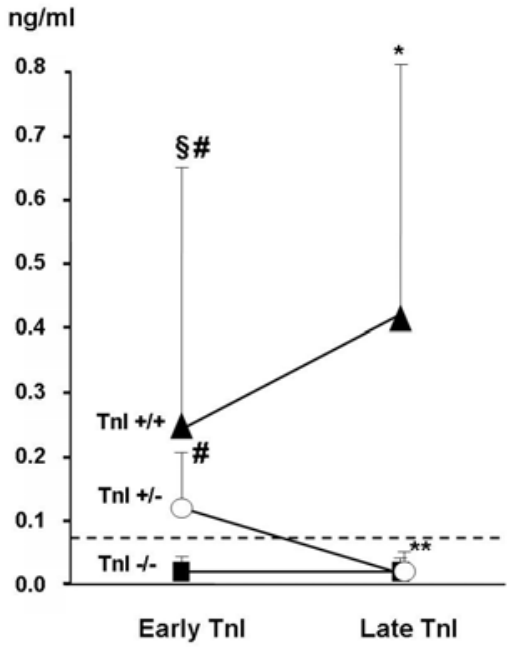

Figure 3: Early and late troponin I (Tnl) values in the three study groups.

${ }^{*} p<0.05$ versus early Tnl; ** $p<0.001$ versus early Tnl; $f l=p<0.001$ versus Tnl+/-; $\# p<0.001$ versus Tnl-/-. From Cardinale et al [31]

considered [31]. As in the previous studies, we evaluated Tnl at baseline and in the first 72 hours after CT (early Tnl); in addition, in all patients, we also measured $\mathrm{Tnl}$ one month later (late Tnl). Three different Tnl patterns were identified in our population (Figure 3): in most patients (70\%), an early and late negative $\mathrm{Tnl}$ value was found. In $21 \%$, Tnl increased soon after CT and normalized one month later. In the remaining $9 \%$ of patients, Tnl positivity was still detectable one month later. 


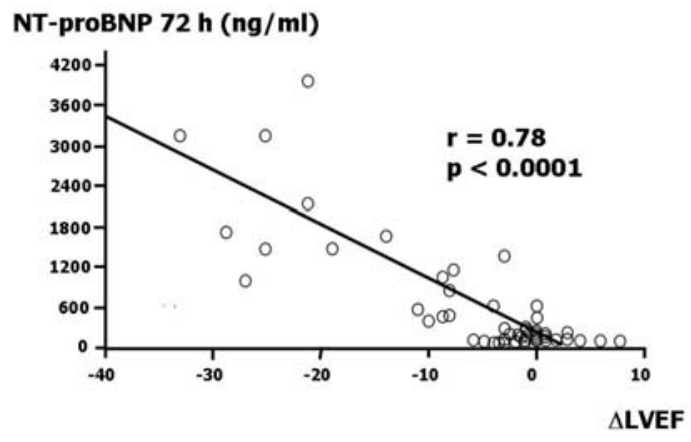

Figure 4: Scatterplot of N-terminal-proB-type natriuretic peptide (NT-proBNP) value at 72 hours against left ventricular ejection fraction (LVEF) changes at 12 months versus baseline.

The Tnl behaviour after CT allowed for the identification of a different cardiac risk, according to the three distinct $\mathrm{Tnl}$ patterns. Patients without Tnl elevation after CT had a good prognosis. Indeed, no significant reduction in LVEF was observed in this group, and a very low incidence of cardiac events (1\%) occurred during the more than three-year long follow-up. Hence, in consideration of the high-negative predictive value of troponin (99\%), low-risk patients $(70 \%$ of patients in this study) that do not require close cardiac surveillance after CT may accurately be identified. In contrast, $\mathrm{Tnl}$ positive patients had a greater incidence of major adverse cardiac events. Among Tnl positive patients, the persistence of the $\mathrm{Tnl}$ increase one month after $\mathrm{CT}$ is consistent with a greater cardiac impairment and a higher incidence of cardiac events than in patients showing only a transient increase $(84 \%$ and $37 \%$, respectively; $p<0.001$ ) [31].

$\mathrm{Tnl}$ increase is also detectable in patients undergoing standard dose of chemotherapy. Experience in our institute shows increased Tnl value in $20 \%$ of patients treated with schedules containing adriamycin-cyclophosphamide (AC); however, Tnl increases, even less frequently (10-15\%), also after the administration of schemes considered less cardiotoxic. More recently, we found $\mathrm{Tnl}$ increase also in patients treated with monoclonal antibodies $(20 \%, 5 \%$ and $8 \%$ in trastuzumab, bevacizumab and rituximab treated patients, respectively). In all patients, the prognostic relevance of $\mathrm{Tnl}$ increase, in terms of LVEF reduction, was confirmed. In our view, Tnl can be proposed as a golden standard marker for the assessment of cardiac safety of both old and new antineoplastic treatments, regardless of the mechanism underlying the cardiac toxic effect.

\section{Haemodynamic markers: NT-proBNP}

Natriuretic peptides have recently emerged as biomarkers potentially useful in the diagnosis and prognostic stratification of patients with heart failure. Particularly, NT-proBNP is released from the heart in response to a cardiac overload [32].

We evaluated the usefulness of NT-proBNP as an early marker able to predict cardiac dysfunction in patients affected by aggressive malignancies who were treated with high-dose CT [33]. We found three distinct NT-proBNP concentration patterns. Thirty-one per cent of patients had no changes in NT-proBNP concentrations during the six samples taken in the 72 hours after CT; $35 \%$ of patients had only a transient increase, with concentrations normalizing at 72 hours. In all these patients, no significant echocardiographic changes were recorded during follow-up. Thirty-three per cent of patients with persistently increased NT-proBNP concentrations at 72 hours developed a significant worsening of both diastolic and systolic properties values during the 12 months of observation. In particular, the echocardiographic monitoring revealed significant increases in mitral deceleration time, in isovolumetric relaxation time and in mitral E/A ratio. LVEF mean value decreased from $62.8 \%$ to $45.6 \%(p<0.001)$. We also found a strong relationship between NT-proBNP value at 72 hours, and LVEF changes at 12 months versus baseline (Figure 4).

Like Tnl, NT-proBNP seems able to give us two kinds of information; the first is qualitative: it is able to identify patients who will develop cardiac dysfunction after CT; the second is quantitative: the absolute value of NT-proBNP at 72 hours 


\section{LVEF \%}

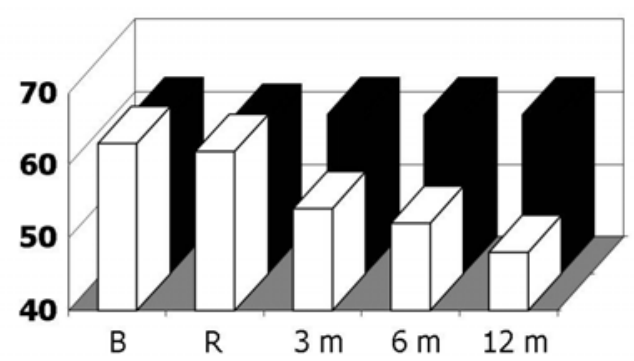

Figure 5: Left ventricular ejection fraction (LVEF) at baseline (before chemotherapy) and during 12-month follow-up in enalapril patients (solid bars) and controls (open bars). $B=$ baseline; $R=$ randomization to enalapril or no therapy (one month after chemotherapy); $p$ value for repeated measures analysis of variance $<0.001$.

reflects the degree of the future left ventricular impairment. The innovative aspect of these markers is that they give us this information at a very early phase, soon after the CT administration, and long before a functional impairment has occurred and could be identified by diagnostic techniques such as echocardiography.

Further prospective studies are needed to clarify whether both markers, Tnl I and NT-proBNP, give the same kind of information, or whether their combination permits better stratification of the cardiac risk of cancer patients treated with CT.

\section{Cardiotoxicity prevention: a new prophylactic approach}

The possibility of identifying patients at higher risk of developing cardiotoxicity by cardiac biomarkers provides a rationale for the development of targeted preventive pharmacological strategies directed at counteracting cardiac dysfunction and cardiac complications occurrence.

Considering the results of our published studies, a possible clinical application of these markers could be the evaluation of pharmacological strategies in selected high-risk patients, with the aim of preventing acute cardiac damage, left ventricular dysfunction and cardiac events. Two different therapeutic strategies could be implemented in order to reduce the clinical impact of cardiotoxicity: (1) use of specific cardiologic treatments given to cancer patients during $\mathrm{CT}$ in the attempt to prevent or blunt the rise of these markers; (2) use of cardiologic treatments given only to selected cancer patients, showing an increase in these markers after CT. This, with the aim of interfering with the natural evolution of cardiac toxicity and prevent the occurrence of left ventricular dysfunction and adverse cardiac events. We hypothesize that cardioprotective therapies that might limit or prevent marker rise after $\mathrm{CT}$, as well as cardiologic treatments that interfere with their persistence, could improve cardiac prognosis of these patients.

Angiotensin-converting enzyme inhibitors (ACEI) have been shown to slow the progression of left ventricular dysfunction in several different clinical settings, including AC-induced CMP $[34,35]$. Furthermore, data referring to experimental models suggest that the cardiac renin-angiotensin system (RAS) plays an important role in the development of $\mathrm{AC}$-induced $\mathrm{CMP}$, and that treatment with ACEI may protect against CT-induced cardiotoxicity [36-41]. According to these data, a prophylactic strategy based on the use of ACEI could prevent cardiotoxicity in selected high-risk patients.

In a recent study from our institute, 473 consecutive cancer patients undergoing high-dose CT were evaluated; of them, 114 (24\%) showed Tnl increase soon after CT and were randomized, either to receive enalapril (ACEl-group, $n=56$ ), or not (controls, $n=58$ ) [42]. Treatment, started one month after $\mathrm{CT}$, was continued for one year. In ACEI-group, LVEF did not change during the treatment period (Figure 5), and a lower incidence of adverse cardiac events was observed (Table 1).

The LVEF was also analysed separately in patients with only transient Tnl increase, and in those with persistent increase. In 
Table 1: Cardiac events during the one-year follow-up in enalapril-treated patients and in controls (modified from Cardinale et al [42])

\begin{tabular}{lcll} 
& $\begin{array}{c}\text { Enalapril group } \\
(\mathbf{n = 5 6 )}\end{array}$ & $\begin{array}{c}\text { Controls } \\
(\mathbf{n = 5 8 )}\end{array}$ & P value \\
\hline Sudden death & $0(0 \%)$ & $0(0 \%)$ & $1.0^{*}$ \\
Cardiac death & $0(0 \%)$ & $2(3 \%)$ & $0.49^{*}$ \\
Acute pulmonary edema & $0(0 \%)$ & $4(7 \%)$ & $0.07^{*}$ \\
Heart failure & $0(0 \%)$ & $14(24 \%)$ & $<0.001$ \\
Armythmias requiring treatment & $1(2 \%)$ & $10(17 \%)$ & 0.01 \\
CUMULATIVE EVENTS & $\mathbf{1}(\mathbf{2} \%)$ & $\mathbf{3 0 ( 5 2 \% )}$ & $<\mathbf{0 . 0 0 1}$ \\
\hline
\end{tabular}

* = by Fisher exact test

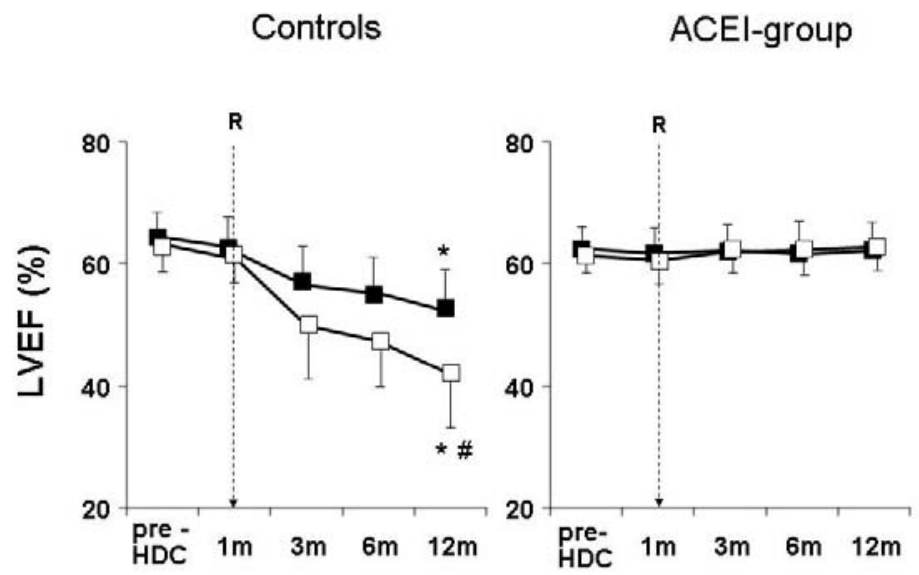

Figure 6: Left ventricular ejection fraction at baseline and during the 12 month follow-up in controls (left panel) and in ACEI-group (right panel), in patients with (open squares) or without (solid squares) persistent troponin I (Tnl) increase $(R=$ randomization).

${ }^{*} p<0.001$ versus baseline and randomization for all time points; $\# p<0.001$ versus patients without persistent Tnl increase. $p$ value for treatment effect $<0.001$. $p$ value for effect of persistent $\mathrm{Tnl}$ increase $<0.001$. $\mathrm{p}$ value for interaction between treatment and persistent $\mathrm{Tnl}$ increase $<0.001$. (From Cardinale et al [42])

agreement with previous findings [31], untreated patients with a persistent (one month after the end of CT) Tnl increase had a greater long-term LVEF reduction than patients with only transient Tnl increase (LVEF decreased from $62 \%$ to $43 \%$ in the former group and from $63 \%$ to $57 \%$ in the latter; $p<0.001$ ). In treated patients, the benefit of enalapril was present in both subgroups: in no patient was LVEF significantly changed (from $61 \%$ to $62 \%$ and from $62 \%$ to $61 \%$, respectively; $p=N S$ ), confirming that patients with persistent Tnl increase are at particularly high risk of cardiotoxicity and may particularly benefit from this preventive therapy (Figure 6) [42].

Although the underlying mechanisms by which ACEl may prevent cardiotoxicity and improve outcome in high-risk CTtreated patients are not completely clear, the induction of a more favourable haemodynamic condition and RAS activation 


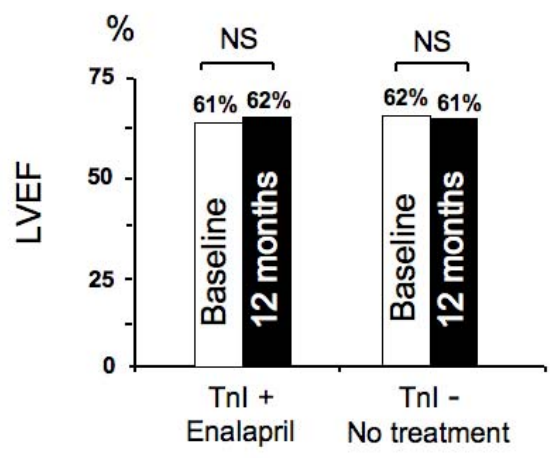

Figure 7: Left ventricular ejection fraction at baseline and 12 months after chemotherapy in troponin I positive patients (TnI+) treated with enalapril and troponin I negative patients (TnI -).

counteraction are likely to play crucial roles. Local inhibition of cardiac ACE could also be involved. Data referring to experimental models suggest that cardiac RAS plays an important role in the development of $\mathrm{AC}$-induced $\mathrm{CMP}$, and that beneficial effects of ACEI in AC-treated animals depends on inhibition of cardiac ACE [36-41]. Moreover, treatment with lisinopril, started after the end of CT, significantly inhibited cardiac ACE activity and improved mortality, cardiac remodelling and cardiac dysfunction in an animal model [36]. Finally, increased oxidative stress has been indicated as a possible primary mechanism in the development of AC-induced cardiac toxicity, and ACEI have been shown to exert antioxidant effects by scavenging free radicals [38].

After this study experience, we applied the new strategy to our daily clinical practice in our institute. The results are summarized in Figure 7. We considered more than 300 patients, we found Tnl positivity in $20 \%$ of patients and we started treatment with enalapril in all cases. In patients without increase of the marker, we did not perform any preventive treatment, and, as expected, no significant changes in LVEF occurred during one-year follow-up. Similarly, in patients showing an early $\mathrm{Tnl}$ increase, we did not observe a significant reduction of systolic function. This finding confirms that cardiotoxicity can effectively be prevented in high-risk patients with this approach, and this preventive strategy can be easily applied in daily clinical practice.

\section{Cardiotoxicity treatment and monitoring}

The most common clinical presentation of cardiotoxicity is a dose-dependent CMP leading to chronic heart failure (HF), frequently occurring after administration of $\mathrm{CT}$ including $\mathrm{AC}$ $[10,11]$.

The prevalence of CT-induced CMP is not well known, as most studies and registries have not specifically analysed this CMP among the several possible causes of acute and chronic HF. From among the few studies in which the aetiology of HF has been evaluated in detail, a prevalence of $1 \%$ of all cases of CMP has been reported [43,44]. However, as reported previously, data from recent oncology literature indicate that more than half of all patients exposed to AC will show some degree of cardiac dysfunction ten to 20 years after CT, and 5\% will develop overt HF. As more than 60,000 patients are treated every year with $A C$ in the United States, the overall incidence of this complication is probably greatly underestimated [7].

Moreover, patients with CMP due to AC are usually considered to have an especially poor prognosis, in comparison with other more frequent forms of CMP [43], with a long-term mortality, such as ischemic and primitive CMP. The relative risk of death in patients with AC-induced CMP is reported as 2.6-fold greater than primitive CMP.

Historically, CT-induced CMP is believed to be refractory to conventional therapy, but many of these data are anecdotal and (1) 
are based on reports including small numbers of patients. In addition, cancer patients with CT-induced CMP have systematically been excluded from large randomized trials evaluating the efficacy of recommended HF therapy.

As a consequence, evidence-based recommendations for management of cancer patients with asymptomatic and symptomatic CT-induced CMP are still lacking, and no definite guidelines are currently adopted. In particular, there is no evidence as to whether the use of ACEI and beta-blocker agents, recommended by international cardiologic guidelines for treatment of HF, can be directly transferred with similar longterm benefits to this particular setting.

In addition, it is very difficult to obtain evidence-based indications from the existing literature, as only an overall adult population of 108 patients can be derived from a total of 11 previous publications, mostly retrospective, without predefined end points, and in which a non-uniform treatment was considered [20,43-52].

In these studies, most patients were treated with digitalis and diuretics, $30 \%$ of patients were treated with $\mathrm{ACEI}, 5 \%$ with betablockers, and only $23 \%$ of patients received a combination of beta-blockers and ACEI. Therefore, even if in some cases patients experienced an improvement of systolic function and relief of symptoms, the anecdotal nature of these observations does not allow us to derive clear indications, in terms of defining the best therapeutic strategy for this form of CMP.

Furthermore, an open critical question remains: whether or not to treat cancer patients with asymptomatic left ventricular dysfunction [7,20,43-52].

Due to the different aetiology and age distribution of this kind of CMP, when compared with the more frequent ischemic or idiopathic CMPs, there is some concern as to whether the use of ACEI and beta-blocking agents can be directly applied to a cancer patient setting. One of the trickier aspects of the late cardiac dysfunction associated with AC is the early asymptomatic nature of the disease. Given the silent nature of the underlying state, many authors have suggested only screening programmes to look for overt $\mathrm{HF}$, and, at present, CT-induced CMP patients are treated only if symptomatic. A crucial issue is whether or not, and eventually how, to treat asymptomatic patients in whom left ventricular dysfunction is detected on routine screening examinations. To date, there is no consensus about what (if anything) can be done to curtail the progression of CT-induced CMP [7]. It is likely that the typical medications used for HF are highly effective, but there may be special concern in cancer patients and, conventionally, the tendency is not to treat aggressively [53].

Preliminary unpublished data from our institute suggest that the time elapsed from the end of CT to the start of HF therapy, with ACEI and, when tolerated, with beta-blocking agents, is a crucial variable for recovery of cardiac dysfunction. Indeed, the likelihood of obtaining a complete LVEF recovery is higher in patients in whom the treatment is initiated within two months from the end of CT. After this time limit, however, this percentage progressively decreases and no complete LVEF recovery is observed after six months.

On the basis of these data, we can speculate that, in most previously published studies, the poor response to therapy was possibly due to the under-use of modern drugs like ACEI and beta-blocking agents, and to the long ( $>12$ months) time elapsed from the end of CT to the beginning of cardiac treatment, that is, when cardiac damage was no longer reversible. This emphasizes the crucial importance of an early detection of cardiotoxicity and suggests that an aggressive approach based on the association of both ACEI and betablocking agents should always be considered, and attempted, in all cases of CT-induced CMP.

Although preventing AC-induced cardiotoxicity remains the optimal target, cardiac function should also be monitored, in patients receiving potentially cardiotoxic $\mathrm{CT}$, in order to detect early cardiac abnormalities while they are still reversible. Indeed, the American College of Cardiology, the American Heart Association, and the American Society of Echocardiography recommend baseline routine evaluations and recurrent re-evaluations by echocardiography in patients undergoing CT [54]. However, this recommendation is often disregarded in asymptomatic patients and in those recovered from the oncologic disease. Oncologists and cardiologists should plan these assessments jointly, sharing therapy decisions and monitoring programmes, in order to prevent both potentially fatal oncologic and cardiologic diseases.

\section{Cardio-oncology: conclusion}

Cardio-oncology is a novel, interdisciplinary, rapidly evolving area of growing interest, based on a comprehensive approach for the management of cancer patients with cardiac diseases. Due to the lack of evidence-based indications and to the urgent need for expertise in this setting, cardio-oncology represents a 
novel, topical research and clinical field, largely unexplored. Involved clinicians and researchers have the ambitious task of investigating this setting, outlining new evidence-based guidelines. This represents a big challenge for both cardiologists and oncologists, and, at the same time, is a stimulating incentive. 


\section{References}

1. Herbst RS, Bajorin DF, Bleiberg $\mathrm{H}$ et al (2006) Clinical cancer advances 2005: major research advances in cancer treatment, prevention, and screening-A report from the American Society of Clinical Oncology $\mathrm{J}$ Clin Oncol 24 190-205 PMID: 16326753 doi: 10.1200/JCO. $\underline{2005.04 .8678}$

2. Kesteloot H, Sans S and Kromhout D (2006) Dynamic of cardiovascular and all-cause mortality in western and eastern Europe between 1970 and 2000 Eur Heart J 27 107-113 PMID: 16204263 doi: 10.1093/eurheartj/ehi511

3. Donfrancesco C, Lo Noce C, Brignoli O et al (2008) Italian network for obesity and cardiovascular disease surveillance: a pilot project BMC Fam Pract 953 PMID: $\underline{18823526}$ doi: 10.1186/1471-2296-9-53

4. Reicher-Reiss H, Jonas M, Goldbourt U et al (2001) Selectively increased risk of cancer in men with coronary heart disease Am J Cardiol 87 459-62 PMID: 11179536 doi: $10.1016 /$ S0002-9149(00)01405-3

5. Kuller LH, Matthews KA and Meilahn EN (2000) Estrogen and women's health: interrelation of coronary heart disease, breast cancer and osteoporosis J Steroid Biochem Mol Biol 74 297-309 PMID: 11162938 doi:10.1016/S0960-0760(00)00106-0

6. Carver JR, Shapiro CL, Ng A et al (2007) American Society of Clinical Oncology clinical evidence review on the ongoing care of adult cancer survivors: cardiac and pulmonary late effects $\mathrm{J}$ Clin Oncol 25 3991-4008 PMID: 17577017 doi: 10.1200/JC0.2007.10.9777

7. Silber JH, Cnaan A, Clark BJ, Paridon SM, Chin AJ, Rychik $\mathrm{J}$ et al (2004) Enalapril to prevent cardiac function decline in long-term survivors of pediatric cancer exposed to anthracyclines J Clin Oncol 22 820-8 PMID: 14990637 doi: $10.1200 / J C 0.2004 .06 .022$

8. Robison LL, Green DM, Hudson M et al (2005) Long-Term Outcomes of Adult Survivors of Childhood. Cancer Results from the Childhood Cancer Survivor Study Cancer 104 2557-64 PMID: 16247780 doi: 10.1002/cncr. $\underline{21249}$

9. Gharib MI and Burnett AK (2002) Chemotherapy-induced cardiotoxicity: current practice and prospects of prophylaxis Eur J Heart Fail 4 235-42 PMID: 12034146 doi: 10.1016/S1388-9842(01)00201-X

10. Pai VB and Nahata MC (2000) Cardiotoxicity of chemotherapeutic agents Drug Safety 22 263-302 PMID: 10789823 doi: $10.2165 / 00002018-200022040-00002$

11. Yeh ETH, Tong AT, Lenihan DJ et al (2004) Cardiovascular complications of cancer therapy. Diagnosis, pathogenesis and management Circulation
109 3122-31 PMID: 15226229 doi:10.1161/01.CIR. $\underline{0000133187.74800 . B 9}$

12. Barry E, Alvarez JA, Scully RE et al (2007) Anthracyclineinduced cardiotoxicity: course, pathophysiology, prevention and management Expert Opin Pharmacother 8 1039-58 PMID: 17516870 doi:10.1517/14656566.8.8. $\underline{1039}$

13. Jones RL and Ewer MS (2006) Cardiac and cardiovascular toxicity of non-antracyclines anticancer drugs Expert Rev Anticancer Ther 6 1229-49 PMID $\underline{17020459}$

14. Wouters KA, Kremer LCM, Miller TL et al (2005) Protecting against anthracyclines-induced myocardial damage: a review of the most promising strategies $\mathrm{Br} \mathrm{J}$ Haematol 131 561-78 PMID: 16351632 doi: 10.1111/j. 1365-2141.2005.05759.x

15. Steinherz LJ, Graham T, Hurwitz R et al (1992) Guidelines for cardiac monitoring of children during and after anthracycline therapy: report of the Cardiology Committee of the Children Cancer Study Group Pediatrics 89 942-9 PMID: 1579408

16. Lipshultz SE, Sanders SP, Goorin AM et al (1994) Monitoring for anthracycline cardiotoxicity Pediatrics 93 433-7 PMID: 7818624

17. Ritchie JL, Bateman TM, Bonow RO et al (1995) Guidelines for clinical use of cardiac radionuclide imaging. Report of the American College of CardiologylAmerican Heart Association Task Force on assessment of diagnostic and therapeutic cardiovascular procedures, in collaboration with the American Society of Nuclear Cardiology J Am Coll Cardiol 25 521-47 PMID: 7829809 doi: 10.1016/07351097(95)90027-6

18. Meinardi MT, Van Der Graaf WTA, Van Veldhuisen DJ et al (1999) Detection of anthracycline-induced cardiotoxicity Cancer Treat Rev 25 237-47 PMID: 10448132 doi: $10.1053 /$ ctrv.1999.0128

19. Schwartz RG, McKenzie WB, Alexander J et al (1987) Congestive heart failure and left ventricular dysfunction complicating doxorubicin therapy. Sevenyear experience using serial radionuclide angiocardiography $A m \mathrm{~J}$ Med 82 1109-18 PMID: $\underline{3605130}$ doi:10.1016/0002-9343(87)90212-9

20. Jensen BV, Skovsgaard $T$ and Nielsen SL (1987) Functional monitoring of anthracycline cardiotoxicity: a prospective, blinded, long-term observational study of outcome in 120 patients Ann Oncol 13 699-709 doi: 10.1093/annonc/mdf132

21. Bristow MR, Mason JW, Billingham ME et al (1978) Doxorubicin cardiomyopathy: evaluation by 
phonocardiography, endomyocardial biopsy and cardiac catherization Ann Intern Med 88 168-75 PMID: $\underline{626445}$

22. Libby P, Bonow RO, Mann DL and Zipes DP (2008) The cancer patient and cardiovascular disease Heart Disease: A Textbook of Cardiovascular Medicine ed E Braunwald (Philadelphia, PA: Saunders Elsevier) pp 210517

23. Cockcroft DW and Gault MH (1976) Prediction of creatinine clearance from serum creatinine Nephron 16 31-41 PMID: 1244564 doi:10.1159/000180580

24. Keefe DL (2001) Anthracycline-induced cardiomyopathy Semin Oncol 28 2-7 PMID: 11552224 doi:10.1016/S00937754(01)90193-9

25. Panteghini M (2004) Role and importance of biochemical markers in clinical cardiology Eur Heart $\mathrm{J}$ 25 1187-96 PMID: 15246636 doi:10.1016/j.ehj.2004.04. $\underline{026}$

26. Jensen JK, Atar D and Mickley H (2007) Mechanism of troponin elevations in patients with acute ischemic stroke Am J Cardiol 99 867-70 PMID: 17350385 doi:10.1016/j.amjcard.2006.10.052

27. Adamcova M, Sterba M, Simunek T et al (2005) Troponin as a marker of myocardiac damage in drug-induced cardiotoxicity Expert Opin Drug Saf 4 457-72 PMID: $\underline{15934853}$ doi: 10.1517/14740338.4.3.457

28. Sparano JA, Brown DL and Wolff AC (2002) Predicting cancer therapy-induced cardiotoxicity. The role of troponins and other markers Drug Safety 25 301-11 PMID: 12020170

29. Cardinale D, Sandri MT, Martinoni A et al (2000) Left ventricular dysfunction predicted by early troponin I release after high-dose chemotherapy J Am Coll Cardiol 36 517-22 PMID: 10933366 doi: 10.1016/S0735-1097 (00)00748-8

30. Cardinale D, Sandri MT, Martinoni A et al (2002) Myocardial injury revealed by plasma troponin I in breast cancer treated with high-dose chemotherapy Ann Oncol 13 710-5 PMID: 12075738 doi:10.1093/ annonc/mdf170

31. Cardinale D, Sandri MT, Colombo A et al (2004) Prognostic value of Troponin I in cardiac risk stratification of cancer patients undergoing high-dose chemotherapy Circulation 109 2749-54 PMID: 15148277 doi: 10.1161/01.CIR.0000130926.51766.CC

32. Clerico A and Emdin M (2004) Diagnostic accuracy and prognostic relevance of the measurement of cardiac natriuretic peptides: a review Clin Chem 50 33-50 PMID: $\underline{14633912}$ doi: $10.1373 /$ dinchem.2003.024760
33. Sandri MT, Salvatici M, Cardinale D et al (2005) N-terminal pro-B-type natriuretic peptide after high-dose chemotherapy: a marker predictive of cardiac dysfunction? Clin Chem 51 1405-10 PMID: 15932966 doi: 10.1373/clinchem.2005.050153

34. Lopez-Sendon J, Swedberg K, McMurray J et al (2004) Expert consensus document on angiotensin converting enzyme inhibitors in cardiovascular disease. The task force on ACE-inhibitors of the European Society of Cardiology Eur Heart J 25 1454-70 PMID: 15302105 doi: 10.1016/j.ehj.2004.06.003

35. Jensen BV, Nielsen SL and Skovsgaard T (1996) Treatment with angiotensin-converting-enzyme inhibitor for epirubicin-induced dilated cardiomyopathy Lancet 347 297-9 PMID: 8569365 doi: 10.1016/S01406736(96)90469-9

36. Okumura K, Jin D, Takai S et al (2002) Beneficial effects of angiotensin-converting enzyme inhibition in adryamicin-induced cardiomyopathy in hamsters Jpn J Pharmacol 88 183-8 PMID: 11928719 doi: 10.1254/jip.88. $\underline{183}$

37. Tokudome T, Mizushige K, Noma $T$ et al (2000) Prevention of doxorubicin (adriamycin)-induced cardiomyopathy by simultaneous administration of angiotensin-converting enzyme inhibitor assessed by acoustic densitometry J Cardiovasc Pharmacol 36 361-8 PMID: 10975594 doi: 10.1097/00005344-200009000$\underline{00012}$

38. Vaynblat M, Shah HR, Bhaskaran D et al (2002) Simultaneous angiotensin converting enzyme inhibition moderates ventricular dysfunction caused by doxorubicin Eur J Heart Fail 4 583-6 PMID: 12413500 doi: 10.1016/S1388-9842(02)00091-0

39. Sacco G, Bigioni M, Evangelista $S$ et al (2001) Cardioprotective effects of zofenopril, a new angiotensin-converting enzyme inhibitor, on doxorubicin-induced cardiotoxicity in the rat Eur J Pharmacol 414 71-8 PMID: 11230997 doi:10.1016/S00142999(01)00782-8

40. Abd El-Aziz MA, Othman Al, Amer M et al (2001) Potential protective role of angiotensin-converting enzyme inhibitors captopril and enalapril against adriamycininduced acute cardiac and hepatic toxicity in rats $\mathrm{J}$ Appl Toxicol 21 469-73 PMID 11746193 doi: 10.1002/ jat.782

41. Maeda A, Honda M, Kuramochi $T$ et al (1997) An angiotensin-converting enzyme inhibitor protects against doxorubicin-induced impairment of calcium handling in neonatal rat cardiac myocytes Clin Exp Pharmacol Physiol 24 720-6 PMID: 9315376 doi: 10.1111/j.1440-1681.1997.tb02119.x 
42. Cardinale D, Colombo A, Sandri MT, Lamantia G, Colombo $\mathrm{N}$, Civelli $\mathrm{M}$ et al (2006) Prevention of high-dose chemotherapy-induced cardiotoxicity in high-risk patients by angiotensin-converting enzyme inhibition Circulation 114 2474-81 PMID: 17101852 doi: 10.1161/ CIRCULATIONAHA.106.635144

43. Felker GM, Thompson RE, Hare JM et al (2000) Underlying causes and long-term survival in patients with initially unexplained cardiomyopathy $N$ Engl J Med 342 1077-84 PMID: 10760308 doi:10.1056/ NEJM200004133421502

44. Adams KF, Dunlap SH, Sueta CA et al (1996) Relation between gender, etiology and survival in patients with symptomatic heart failure $\mathrm{J} \mathrm{Am}$ Coll Cardiol 28 1781-8 PMID: 8962567 doi: 10.1016/S0735-1097(96)00380-4

45. Lefrak EA, Pitha J, Rosenheim S and Gotilieb JA (1973) A clinicopathologic analysis of adriamycin cardiotoxicity Cancer 32 302-14 PMID: 4353012 doi: 10.1002/10970142(197308)32:2<302::AID-CNCR2820320205>3.0.CO;2$\underline{2}$

46. Cohen M, Kronzon I and Lebowitz A (1982) Reversible doxorubicin-induced congestive heart failure Arch Intern Med 142 1570-1 PMID: 7103641 doi: 10.1001/ archinte.142.8.1570

47. Jensen BV, Nielsen SL and Skovsgaard T (1996) Treatment with angiotensin-converting-enzyme inhibitor for epirubicin-induced dilated cardiomyopathy Lancet 347 297-9 PMID: 8569365 doi: 10.1016/S0140$\underline{6736(96) 90469-9}$

48. Fazio $S$, Calmieri EA, Ferravate $B$, Bonè, $F$, Biondi $B$ and Saccà L (1998) Doxorubicin-induced cardiomyopathy treated with carvedilol Clin Cardiol 21 777-9 PMID: $\underline{9789703}$ doi: $10.1002 /$ clc. 4960211017
49. Noori A, Lindenfeld J, Wolfel E, Ferguson D, Bristow MR and Lowes BD (2000) Beta-blockade in adriamycininduced cardiomyopathy $\mathrm{J}$ Card Fail 6 115-9 PMID: 10908085 doi:10.1016/S1071-9164(00)90013-7

50. Mukai Y, Yoshida T, Nakaike R, Mukai N, Iwato K, Kyo T et al (2004) Five cases of anthracycline-induced cardiomyopathy effectively treated with carvedilol Intern Med 43 1087-8 PMID: 15609710 doi: 10.2169/ internalmedicine.43.1087

51. Tallaj JA, Franco V, Rayburn BK, Pinderski L, Benza RL, Pamboukian S et al (2005) Response of doxorubicininduced cardiomyopathy to the current management strategy of heart failure $\mathrm{J}$ Heart Lung Transplant 24 2196-201 PMID: 16364871 doi: 10.1016/j.healun.2004.12. $\underline{108}$

52. Tabet JY, Meurin $P$, Ben Driss A, Berthaux $X$, Weber $H$, Renaud $\mathrm{N}$ et al (2006) Beta-blockade intolerance in anthracycline-induced cardiomyopathy Int J Cardiol 106 132-4 PMID: 15992949 doi: 10.1016/j.ijcard.2004.12.052

53. Lenihan DJ (2006) Diagnosis and management of heart failure in the cancer patient Cancer and the Heart ed MS Ewer and ETH Yeh (Hamilton: BC Decker Inc) pp 64-67

54. Cheitlin MD, Armstrong WF, Aurigemma GP, Beller GA, Bierman FZ, Davis JL et al (2003) ACCIAHA/ASE 2003 guideline update for the clinical application of echocardiography: summary article: a report of the American College of CardiologylAmerican Heart Association Task Force on Practice Guidelines (ACCIAHA/ASE Committee to Update the 1997 Guidelines for the Clinical Application of Echocardiography) Circulation 108 1146-62 PMID $\underline{12952829}$ doi: 10.1161/01.CIR.0000073597.57414.A9 